\title{
UPAYA PENINGKATAN KESEHATAN TENTANG BAHAYA HIPERKOLESTEROLEMIA
}

\author{
Salvita Fitrianti' ${ }^{1}$, Miko Eka Putri ${ }^{2)}$, Rahmi Dwi Yanti ${ }^{3)}$ \\ 1,2,3 Program Studi S1 Keperawatan, STIKes Baiturrahim Jambi \\ Email:putri29iwan@gmail.com
}

\begin{abstract}
High cholesterol levels are one of the causes of metabolic problems that cause heart disease, blood vessels, and diseases that are associated with blockages in blood vessels. The accumulation of the amount of fat deposits on the walls of blood vessels can cause a blockage in the blood vessels or known as atherosclerosis. The purpose of this service is to increase people's knowledge about the dangers of cholesterol. This service was carried out in December 2018 at the home of the RT 05 Payo Sigadung house. The target of this activity is Payo Sigadung RT 05 Rawa Sari Village. Activities consist of several processes 1). Check cholesterol levels, 2). Pre-test the public's knowledge about the dangers of hypercholesterolemia, 3) Conduct health education, 4) Perform a test of knowledge test after being given a health education about cholesterol. The output of this activity is 1). People who take counseling are expected to be able to understand the effects of high cholesterol and cholesterol signs, 2) Results of checking cholesterol levels. The results of the implementation of this activity were $85 \%$ of the community were able to answer questions given and understand about hypercholesterolemia. With the increase in public knowledge about the dangers of hypocholesterolemia, it is hoped that the community will be able to implement maintaining the health of most foods so that they can avoid hypercholesterolemia.
\end{abstract}

Keywords: Hypercholesterolemia; Health Education; People

\begin{abstract}
ABSTRAK
Kadar kolesterol yang tinggi merupakan salah satu penyebab masalah metabolik yang menyebabkan timbulnya penyakit jantung, pembuluhdarah, serta penyakit-penyakit yang berhubungan dengan adanya sumbatan pada pembuluh darah. Adanya penumpukan jumlah deposit lemak pada dinding pembuluh darah dapat menyebabkan suatu sumbatan pada pembuluh darah atau yang dikenal dengan sebutan atherosklerosis. Tujuan dari pengabdian ini adalah untuk meningkatkan pengetahuan warga tentang bahaya kolesterol. Pengabdian ini dilakukan pada bulan Desember 2018 bertempat di rumah ketua RT 05 Payo Sigadung. Sasaran kegiatan ini masyarakat Payo Sigadung RT 05 Kelurahan Rawa Sari. Kegiatan terdiri dari beberapa proses 1). Melakukan pemeriksaan kadar kolesterol, 2). Melakukan pretest pengetahuan masyarakat tentang bahaya hiperkolesterolemia, 3) Melakukan Pendidikan kesehatan, 4) Melakukan Postest pengetahuan setelah diberikan pendidikan kesehatan tentang kolesterol. Luaran dari kegiatan ini adalah 1). Masyarakat yang mengikuti penyuluhan diharapkan mampu memahami tentang dampak kolesterol yang tinggi dan tanda-tanda kolesterol , 2) Hasil pemeriksaan kadar kolesterol. Hasil pelaksanaan kegiatan ini adalah $85 \%$ masyarakat mampu menjawab pertanyaan yang diberikan dan mengerti tentang hiperkolesterolemia. Dengan meningkatnya pengetahuan masyarakat tentang bahaya hipekolesterolemia, diharapkan masyarakat mampu menerapkan menjaga kesehatan teruatama makanan sehingga dapat terhindar dari hiperkolesterolemia.
\end{abstract}

Kata Kunci : Hiperkolesterolemia; Pendidikan Kesehatan; Masyarakat 


\section{PENDAHULUAN}

Kolesterol merupakan salah satu dari golongan lemak (lipida) padat yang berwujud seperti lilin. Kolesterol bersifat aterogenik atau sangat mudah menempel yang kemudian membentuk plak pada dinding pembuluh darah. Kolesterol yang diproduksi oleh tubuh terdiri dari 2 jenis, yaitu kolesterol HDL (High Density Lipoprotein) yang biasa disebut dengan kolesterol baik dan kolesterol LDL (Low Density Lipoprotein) disebut dengan kolesterol jahat. Kolesterol LDL akan menumpuk pada dinding pembuluh darah arteri koroner yang menyebabkan penyumbatan, karena itu LDL disebut sebagai kolesterol jahat (Kowalski, 2010). Kelebihan kadar kolesterol dalam darah disebut dengan hiperkolesterolemia (Mayes, 2003).

Hiperkolesterolemia dapat diklasifikasikan berdasarkan penyebabnya menjadi 2 yaitu hiperkolesterolemia primer terutama disebabkan oleh faktor genetik, usia, jenis kelamin dan hiperkolesterolemia sekunder yang disebabkan oleh kebiasaan diet lemak jenuh, kurangnya aktivitas fisik, obesitas serta sindrom nefrotik (Matfin, 2009).

Kadar kolesterol yang terlalu tinggi dan berlebihan di dalam darah akan sangat berbahaya bagi kesehatan jantung dan pembuluh darah. Kadar kolesterol yang tinggi merupakan salah satu penyebab masalah metabolik yang menyebabkan timbulnya penyakit jantung, pembuluh darah, serta penyakit-penyakit yang berhubungan dengan adanya sumbatan pada pembuluh darah. Adanya penumpukan jumlah deposit lemak pada dinding pembuluh darah dapat menyebabkan suatu sumbatan pada pembuluh darah atau yang dikenal dengan sebutan atherosklerosis. Penyumbatan yang terjadi pada pembuluh darah koroner jantung akan menyebabkan penyakit jantung koroner (PJK). Tidak hanya itu, penyumbatan (atherosklerosis) juga dapat terjadi pada dinding pembuluh darah otak, ginjal, alat gerak, dan berbagai organ lainnya (Garnadi, 2012).

Saat ini PJK menjadi penyebab kematian utama di negara berkembang, angka kematiannya diperkirakan meningkat hingga $28 \%$ per tahun. Data WHO tahun 2013 menunjukkan bahwa PJK menduduki posisi keempat penyakit tidak menular dengan angka kejadian sebesar $63 \%$ dari total kematian. Data Riskesdas tahun 2013 menunjukkan prevalensi penyakit jantung koroner di Indonesia berdasarkan wawancara terdiagnosis dokter sebesar $0,5 \%$, dan berdasarkan terdiagnosis dokter atau gejala sebesar $1,5 \%$.

Penelitian Wulandari, dkk (2015) tentang pemeriksaan kadar kolesterol dan tekanan darah pada masyarakat kota Jambi sebagai skrining awal penyakit jantung coroner dari 60 orang didapatkan sejumlah 40 orang dalam kondisi normal dan 20 orang mengalami hiperkolesterolemia.

Indikasi tingginya kolesterol di kota Jambi disebabkan bebera faktor selain jumlah penduduk yang padat salah satunya di Daerah Payo Sigadung yang merupakan kawasan pemukiman kumuh, dapat dilihat dari kondisi fisiknya dimana kepadatan bagunan di kampung Payo Sigadung cukup tinggi dan kepadatan penghuni dalam satu rumah yang mencapai 10-20 anggota keluarga. Pada tahun 2017 tercatat ada $179 \mathrm{KK}$ yang tinggal di Payo Sigadung yang diperuntukkan kepada 925 jiwa penduduk.

Maka dari itu penulis tertarik melaksanakan kegiatan penyuluhan tentang "Pendidikan Kesehatan Tentang Pendidikan Kesehatan Tentang Kolesterol RT 5 Payo Sigadung”. 


\section{TARGET DAN LUARAN}

Target dari kegiatan ini adalah : Masyarakat RT 05 Payo Sigadung yang memiliki riwayat hiperkolesterolemia atau yang memiliki keluhan atau gejala yang mengarah kepada hiperkoleterolemia.

\section{METODE PELAKSANAAN}

Kegiatan pengabdian ini dilakukan kepada masyarakat RT 05 Payo Sigadung pada bulan Desember 2018 bertempat di Rumah Ketua RT. Metode pelaksanaan kegiatan ini berupa survey, observasi, wawancara, ceramah, tanya jawab, simulasi dan demonstrasi serta pemberian pendidikan kesehatan. Prosedur pelaksanaan kegiatan pengabdian masyarakat secara sistematis adalah :

1. Melakukan pemeriksaan kolesterol

2. Melakukan pre tes pengetahuan tentang hiperkolesterolemia

3. Memberikan pendidikan kesehatan tentang bahaya Hiperkolesterolemia

4. Melakukan post tes pengetahuan tentang hiperkolesterolemia

\section{HASIL DAN PEMBAHASAN}

Pelaksanaan pengabdian ini dilaksanakan melalui 3 proses, mulai dari persiapan sampai dengan evaluasi hasil. Pada proses persiapan diawali dengan permintaan izin ke ketua RT 05. Semua sesuai dengan rencana, persiapan alat dan semua media tersedia dengan baik sehingga semua kegiatan berjalan dengan lancar. Peran dan tugas masing-masing struktur organisasi sesuai dengan uraian tugas yang telah ditetapkan bersama, baik sebagai moderator, presenter, fasilitator, observer dan notulen. Pada proses pelaksanaan yang dihadiri sebanyak 30 orang warga sangat antusias. Selama penyuluhan Selama pelaksanaan ada beberapa warga masyarakat yang bertanya terkait dengan hiperkolesterol. Peserta yang hadir berperan aktif dalam menjawab pertanyaan selama diskusi berlangsung. Pemeriksaan kolesterol pada semua peserta penyuluhan sudah terlaksana dengan baik. Hasil pemeriksaan menunjukkan bahwa dari 30 peserta, sebanyak $(75 \%)$ warga memiliki nilai kolesterol tinggi. Dengan diadakan pendidikan kesehatan diharapkan masyarakat mampu memahami bahaya hiperkolesterolemia sehingga masyarakat dapat mencegah terjadinya hiperkolesterol.

\section{KESIMPULAN DAN SARAN}

\section{Kesimpulan}

Setelah melakukan pendidikan kesehatan $85 \%$ masyarakat mampu mengerti tentang hiperkolesterolemia.

\section{Saran}

Diharapkan masyarakat mampu menerapkan menjaga kesehatan teruatama makanan sehingga dapat terhindar dari hiperkolesterolemia.

\section{DAFTAR PUSTAKA}

Balitbang Kemenkes RI. 2013. Riset Kesehatan Dasar; RISKESDAS. Jakarta: Balitbang Kemenkes RI.

Garnadi, Y. 2012. Hidup Nyaman dengan Hiperkolesterol. Jakarta: PT Agro Media Pustaka.

Mayes P.A. 2003. Lipid yang Memiliki Makna Fisiologis. Dalam: Murray R.K., Granner D.K., Mayes P.A., Rodwell V.W., ed: Biokimia Harper. Edisi 25. Jakarta: EGC. Hal 148-159.

Matfin, G., Porth, C.M., 2009. Structure and Function of the Cardiovascular System. In: Pathophysiology Concepts of Aletered Health States. 
Jurnal Abdimas Kesehatan (JAK) Vol 1,No.2, Juni 2019

p-ISSN: 2655-9266

e-ISSN: 2655-9218

Philadelphia: Lippincott Williams and Wilkins,482- 483.

Wulandari, dkk (2015). Jurnal Pengabdian pada Masyarakat. Volume 31, Nomor 4 Oktober - Desember 2016

Tentang Pemeriksaan Kadar Kolesterol Dan Tekanan Darah Pada Masyarakat Kota Jambi Sebagai Skrining Awal Penyakit Jantung Koroner. Universitas Jambi 